\title{
High mass loading, binder-free MXene anodes for high areal capacity Li-ion batteries
}

\author{
Seon Joon Kim ${ }^{a, b}$, Michael Naguib ${ }^{a}$, Mengqiang Zhao ${ }^{a}$, Chuanfang Zhang ${ }^{a, c}$, Hee-Tae Jung ${ }^{b}$, \\ Michel W. Barsoum ${ }^{a}$, Yury Gogotsi ${ }^{a}$ *
}

${ }^{a}$ A. J. Drexel Nanomaterials Institute and Department of Materials Science and Engineering, Drexel University, Philadelphia, PA 19104, USA

${ }^{\mathrm{b}}$ Department of Chemical and Biomolecular Engineering (BK-21 Plus), Korea Advanced Institute of Science and Technology, 291 Daehak-ro, Yuseong-gu, Daejeon 305-701, Korea

${ }^{c}$ State Key Laboratory of Chemical Engineering, East China University of Science and Technology, Shanghai 200237, China

\author{
AUTHOR INFORMATION \\ Corresponding Author: Tel: +1-215-895-6446, Fax: +1-215-895-1934 \\ E-mail address: gogotsi@drexel.edu (Y. Gogotsi)
}




\title{
Electrochimica Acta
}

\begin{abstract}
Though anodes with high Li gravimetric capacities, beyond commercial graphite, have been intensively studied, gravimetric capacity does not precisely reflect the performance of a packed cell. Li anodes with high mass loadings, which can achieve high areal capacities, are required for many commercial applications. Herein, anodes with high mass loadings were fabricated using two-dimensional transition metal carbides (MXenes). Powders of the latter were cold pressed, without binders, at a pressure of $1 \mathrm{GPa}$, to create $\sim 300 \mu \mathrm{m}$ thick, free-standing discs. When $\mathrm{Ti}_{3} \mathrm{C}_{2}$ was used as the anode for lithium, the initial reversible areal capacity was $\sim 15 \mathrm{mAh} / \mathrm{cm}^{2}$, which decreased to $5.9 \mathrm{mAh} / \mathrm{cm}^{2}$ after 50 cycles, but the decrease after the first $\sim 20$ cycles was very gradual. The latter is one of the highest values ever reported to date. When $\mathrm{Nb}_{2} \mathrm{C}$ was used as the anode instead, the initial reversible capacity was $\sim 16 \mathrm{mAh} / \mathrm{cm}^{2}$; this value decreased to 6.7 $\mathrm{mAh} / \mathrm{cm}^{2}$ after 50 cycles, which is about a $14 \%$ increase compared to $\mathrm{Ti}_{3} \mathrm{C}_{2}$. As the research on MXenes for lithium ion batteries has just begun, there is certainly room for further improving the electrochemical performance of MXene electrodes.
\end{abstract}

\section{KEYWORDS}

MXene; 2D carbide; Li-ion Battery; Anode; Areal capacity 


\section{Introduction}

For at least two decades now, lithium-ion batteries (LIBs) have been used as the main energy source for electronic devices due to their high energy density [1, 2]. Today their applications expanded to electric vehicles (EV) and grid energy storage [3, 4]. Commercial batteries employ graphite as the anode, in which Li ions intercalate between the graphite layers to form $\mathrm{Li}_{x} \mathrm{C}_{6}(x \leq 1)$, with a theoretical capacity of $372 \mathrm{mAh} / \mathrm{g}$ [5]. As new applications, such as EVs, require higher energy densities, much research has being dedicated to increase the gravimetric capacity and replace current graphite LIB anodes with two-dimensional, and other novel materials [6-10]. Due to their high gravimetric capacities, materials that form alloys with Li, such as Si [11, 12], Ge [13], and Sn [14] have been explored extensively. Among those, Si with a theoretical specific capacity of $\sim 4200 \mathrm{mAh} / \mathrm{g}$ - has been intensively studied as a potential substitute for current graphite anodes $[11,15]$ and is already being incorporated into commercial batteries.

Most of the studies on LIB materials emphasize gravimetric capacities. And while the latter is important in some applications, there are other metrics such as areal and volumetric capacities that are as, if not more, important for some device applications [16]. This is especially true of the latest generation of portable devices where volume is more important than weight. Even more importantly, in many cases, the specific values reported are obtained on electrodes with very low mass loadings of the active material. Since, in most cases, the capacity does not scale linearly with electrode thickness and other components - which have non-negligible weights - have to also be taken into consideration, overly optimistic gravimetric capacity values reported for many nanostructured electrodes do not translate into performance of real batteries 
[16]. Lastly, and most importantly, a match between the specific capacities of the anodes and cathodes needs to be established. This is especially true since the best capacities of cathodes for $\mathrm{Li}$ batteries at this time are in the range of $200 \mathrm{mAh} / \mathrm{g}$ [17] and up to $4.1 \mathrm{mAh} / \mathrm{cm}^{2}$ [18], and an anode with a matching areal capacity is needed. In matching cathode and anode performances, the areal capacity $\left(\mathrm{mAh} / \mathrm{cm}^{2}\right)$ is a critical consideration as the anode and the cathode face each other in a typical battery [19]. High-density electrodes are important, as dense films directly lead to higher volumetric and areal capacities [20].

Recently, a family of two-dimensional (2D) transition metal carbides (e.g. $\mathrm{Ti}_{3} \mathrm{C}_{2}, \mathrm{Ti}_{2} \mathrm{C}$, $\mathrm{Nb}_{2} \mathrm{C}, \mathrm{V}_{2} \mathrm{C}$, etc.), called MXenes was discovered [21-24]. MXenes are produced by etching away the A layers from $M_{n+1} A X_{n}$ (MAX phases), in which " $M$ " represents a transition metal, " $A$ " are elements in the groups 13-16 (Al, Ge, Si, etc.), and " $\mathrm{X}$ " represents carbon and/or nitrogen and n $=1$ to 3 . Given that the MXene surfaces are terminated with $\mathrm{OH}$, and $\mathrm{F}$ groups resulting from the etching process, it is more accurate to refer to them as $M_{n+1} X_{n} T_{x}$, where $T$ represents the surface terminating groups, such as $\mathrm{O}, \mathrm{F}$ and $\mathrm{OH}$. As-prepared MXenes exist in a multilayered structure, which appears as planar sheets stacked in flakes. The multilayered structures can be delaminated into single-layer flakes by sonication [25-28]. Due to their high specific surface areas, metallic conductivity, and hydrophilic surfaces, MXenes have shown outstanding performance as electrodes for supercapacitors [26-28]. MXenes are also promising anode materials for LIBs due to their excellent conductivity and cation intercalation capability $[29,30]$. Capacities in the range 600-700 $\mathrm{mAh} / \mathrm{g}$ have been predicted, depending on the MXene structure and composition [3134]. And indeed, high-rate anodes have been demonstrated using relatively thin films of delaminated $\mathrm{Ti}_{3} \mathrm{C}_{2}$ [25], but a number of issues typical of early stage material development, 


\section{Electrochimica Acta}

including first cycle irreversibility, sloped charge-discharge behavior and material loading still need to be addressed.

The objective of this work is to show that MXenes can be used for manufacturing electrodes with high areal capacities. Herein, we report on the use of $\mathrm{Ti}_{3} \mathrm{C}_{2} \mathrm{~T}_{\mathrm{x}}$ discs with thicknesses of a few tens to hundreds of micrometers and densities up to $2.52 \mathrm{~g} / \mathrm{cm}^{3}$ to develop LIB anodes with high areal capacities. The discs, which were prepared by cold pressing of multilayered $\mathrm{Ti}_{3} \mathrm{C}_{2} \mathrm{~T}_{\mathrm{x}}$ powders at room temperature, were freestanding and no binder was used.

\section{Experimental}

\subsection{Preparation of $\mathrm{Ti}_{3} \mathrm{C}_{2}$ and $\mathrm{Nb}_{2} \mathrm{C}$ MXenes}

$\mathrm{Ti}_{3} \mathrm{C}_{2} \mathrm{~T}_{\mathrm{x}}$ used in this study was produced by etching $\mathrm{Al}$ from the MAX phase, $\mathrm{Ti}_{3} \mathrm{AlC}_{2}$ powder prepared by mixing commercial $\mathrm{Ti}_{2} \mathrm{AlC}$ powder (Kanthal, Sweden) with $\mathrm{TiC}$ in a $1: 1$ molar ratio. The mixture was then heated at $1350^{\circ} \mathrm{C}$ under argon, Ar, for $2 \mathrm{~h}$ in a tube furnace, then taken out after cooling down to room temperature. The obtained MAX phase $\mathrm{Ti}_{3} \mathrm{AlC}_{2}$ was crushed and sieved through a 400 mesh sieve to give a powder with the particle size below 38 $\mu \mathrm{m}$. The latter was immersed in a $50 \mathrm{wt} . \%$ aqueous HF solution at room temperature for $18 \mathrm{~h}$, while stirring, as described in Refs. [21, 22]. Then, the solution was rinsed and centrifuged with DI water several times to rid of residual HF, then dried to obtain $\mathrm{Ti}_{3} \mathrm{C}_{2} \mathrm{~T}_{\mathrm{x}}$ powders. $\mathrm{Nb}_{2} \mathrm{AlC}$ powders were produced by mixing Nb (Atlantic Equipment Engineers, Bergenfield, USA, 99.8 wt. \% purity, -325 mesh), Al (Alfa Aesar, Ward Hill, USA, 99.5 wt. \% purity, -325 mesh), and graphite (Alfa Aesar, Ward Hill, USA, 99 wt. \% purity, -300 mesh) in an atomic ratio of 2:1.1:1, in a ball mill for $18 \mathrm{~h}$. The powders were heated to $1600^{\circ} \mathrm{C}$ under Ar for $4 \mathrm{~h}$ in a tube furnace, then cooled down to room temperature. Obtained powders were sieved through a 400 mesh sieve. 
$\mathrm{Nb}_{2} \mathrm{C}$ was similarly produced by immersing $\mathrm{Nb}_{2} \mathrm{AlC}$ powders in $50 \mathrm{wt}$. $\% \mathrm{HF}$ for $40 \mathrm{~h}$ at $55^{\circ} \mathrm{C}$ while stirring. Then, the solution was also rinsed and centrifuged with DI water, and dried to obtain $\mathrm{Nb}_{2} \mathrm{CT}_{\mathrm{x}}$ powders, as described in Ref. [35].

\subsection{Electrochemical measurements}

CR2016-type coin cells were assembled in an Ar-filled glove box with a moisture level below $1 \mathrm{ppm}$. Li foil was used as the half-cell counter electrode, and glass fiber (Whatman GF/A), and Celgard propylene membranes were used as separators. Stainless steel spacers were also inserted in the cell to ensure good electrical contact between the layers. A 1:1 in volume mixture of $1 \mathrm{M} \mathrm{LiPF}_{6}$ dissolved in a mixture of ethylene carbonate (EC) with diethyl carbonate (DEC) was used as the electrolyte. Cells were galvanostatically cycled by an Arbin BT2000 instrument (Arbin Instruments, TX, USA), where cells were cycled at various rates. Cyclic voltammetry (CV) tests were performed by a Biologic VMP-3 (Biologic SAS, France) instrument. Cells were left at open circuit voltage (OCV) for at least $12 \mathrm{~h}$ prior to electrochemical testing. All of the electrochemical measurements were carried out at $25^{\circ} \mathrm{C}$. The reported values for gravimetric, volumetric, and areal capacities are based on the entire weight, volume, and area of the electrode, respectively.

\section{Results and Discussion}

The layered structure of the $\mathrm{Ti}_{3} \mathrm{C}_{2} \mathrm{~T}_{\mathrm{x}}$ powders, similar to thermally expanded graphite, can be seen in the scanning electron microscope (SEM) image in Fig. 1a. Each $\mathrm{Ti}_{3} \mathrm{C}_{2} \mathrm{~T}_{\mathrm{x}}$ particle was a few micrometers in size. To obtain $\mathrm{Ti}_{3} \mathrm{C}_{2} \mathrm{~T}_{\mathrm{x}}$ discs with high densities and high mass loadings, the MXene powders were loaded in a $25 \mathrm{~mm}$ diameter die and cold pressed at room temperature under a load corresponding to a stress of $1 \mathrm{GPa}$. This procedure resulted in binder free, free- 
standing $\mathrm{Ti}_{3} \mathrm{C}_{2} \mathrm{~T}_{\mathrm{x}}$ discs (Fig. 1 b, bottom) that varied in thickness from tens to hundreds of micrometers. The original discs $-25 \mathrm{~mm}$ in diameter - were cut into smaller pieces that fit into the coin cells. The densities of the additives-free $\mathrm{Ti}_{3} \mathrm{C}_{2}$ pressed discs were in the range of 2.14$2.52 \mathrm{~g} / \mathrm{cm}^{3}$. That density range is about three times higher than a MXene electrode made by the conventional slurry casting method, which had a density of $0.8 \mathrm{~g} / \mathrm{cm}^{3}[29]$.

The fracture surface of a pressed disc shows densely packed and randomly arranged $\mathrm{Ti}_{3} \mathrm{C}_{2}$ particles (Fig. 1c, 1d). The XRD pattern from the top surface of a disc (Fig. 1e) showed a strong (0002) peak at $2 \theta=8.9^{\circ}$, which corresponds to a $c$-lattice parameter $(c-\mathrm{LP})$ of $1.98 \mathrm{~nm}$; a value that is comparable to previous studies [21]. The following peaks correspond to higher order reflections viz. (0004), (0006) and (0008). The characteristic peaks of $\mathrm{Ti}_{3} \mathrm{C}_{2}$ flakes show that they have retained their lattice structure after being pressed into the discs. The peak at $61^{\circ}$ is due to the (110) planes, i.e. evidence that the flakes are stacked along [0001]. Said otherwise, they were not delaminated. 

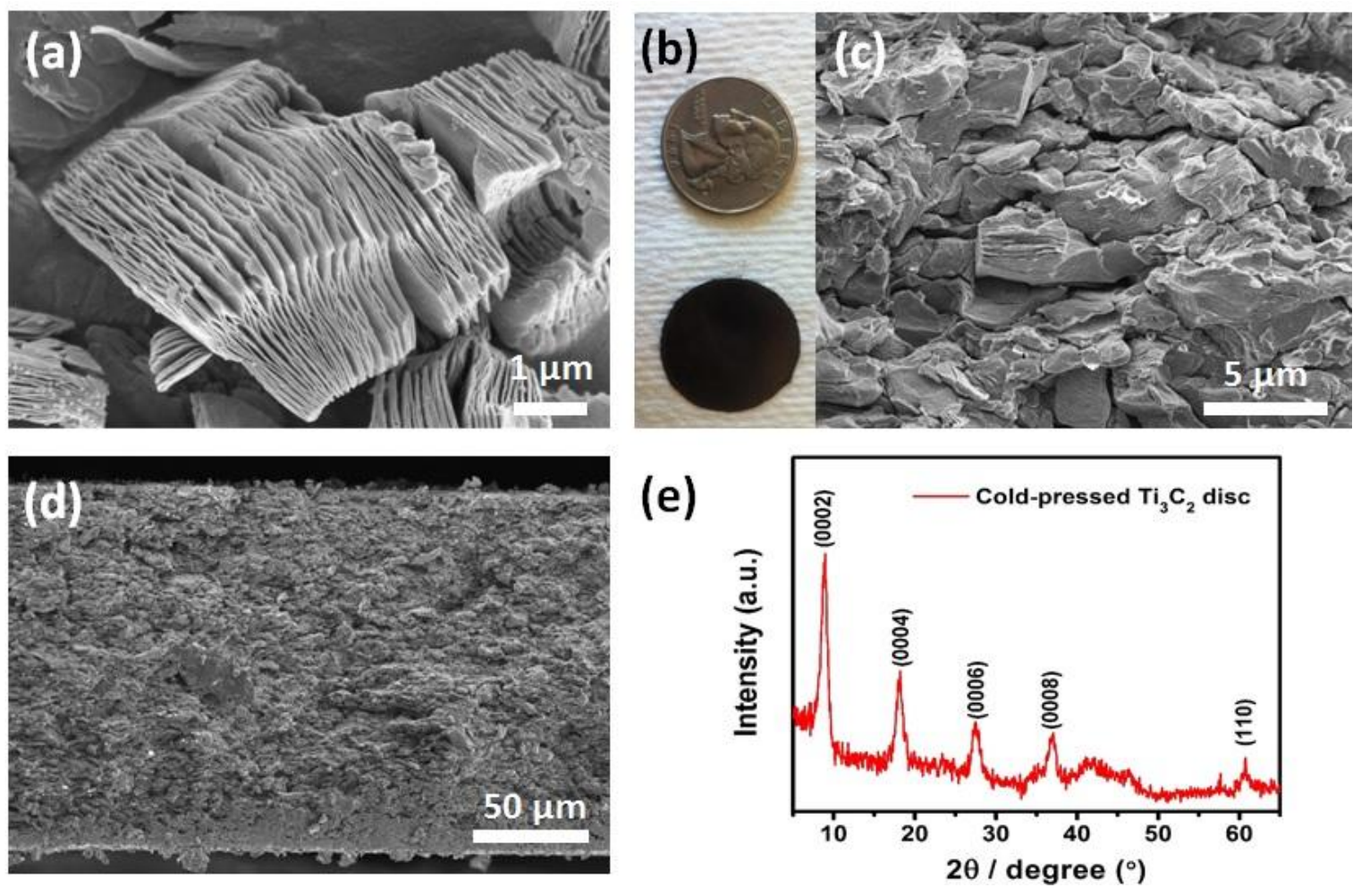

Fig. 1. (a) Scanning electron microscope (SEM) micrographs of exfoliated $\mathrm{Ti}_{3} \mathrm{C}_{2}$ multilayer flakes. (b) Image of a cold-pressed disc (bottom), roughly $25 \mathrm{~mm}$ in diameter. (c) SEM image of the fracture surface of a pressed $\mathrm{Ti}_{3} \mathrm{C}_{2}$ disc, (d) entire cross-section of the disc. (e) X-ray diffraction (XRD) pattern of a pressed $\mathrm{Ti}_{3} \mathrm{C}_{2} \mathrm{~T}_{\mathrm{x}}$ disc.
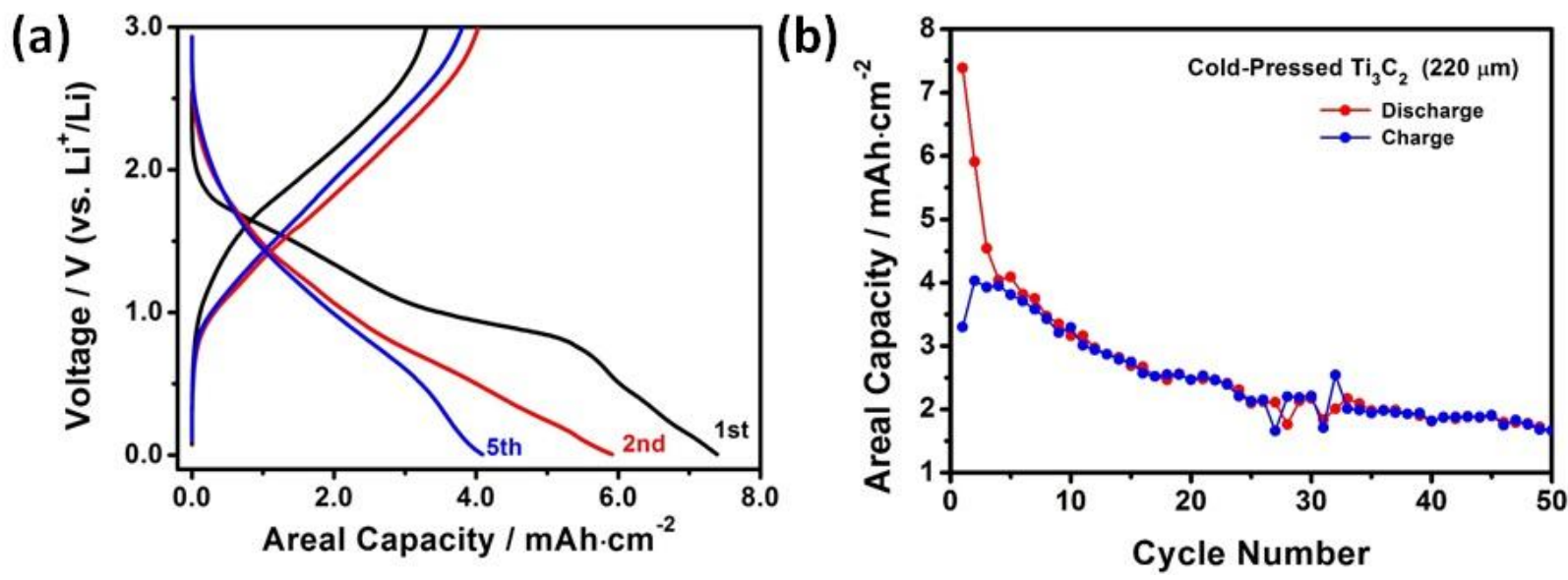

Fig. 2. Electrochemical tests performed on a pressed $\mathrm{Ti}_{3} \mathrm{C}_{2} \mathrm{~T}_{\mathrm{x}}$ electrode. (a) Charge/discharge curve at a current density of $1.5 \mathrm{~mA} / \mathrm{cm}^{2}$. A voltage plateau, due to SEI formation can be seen in the first cycle. (b) Areal capacity vs. cycle number at a current density of $1.5 \mathrm{~mA} / \mathrm{cm}^{2}$, which corresponds to a $\mathrm{C} / 3$ rate. The blue points were obtained on charging and the red on discharging. 
Cells were assembled with a $\mathrm{Ti}_{3} \mathrm{C}_{2} \mathrm{~T}_{\mathrm{x}}$ mass loading of $50 \mathrm{mg} / \mathrm{cm}^{2}$. Cyclic voltammetry $(\mathrm{CV})$ and galvanostatic cycling were used to evaluate the performance of the pressed MXene anodes. The CV tests (Fig. S1a) were carried out at a scan rate of $0.2 \mathrm{mV} / \mathrm{s}$. Capacity values were calculated from the galvanostatic charge/discharge curves (Fig. 2a), where cells were cycled between $5 \mathrm{mV}$ and $3 \mathrm{~V}$ vs. $\mathrm{Li}^{+} / \mathrm{Li}$, at a current of $30 \mathrm{~mA} / \mathrm{g}$, which corresponds to a charging rate of $\mathrm{C} / 3$. The areal capacity was $1.5 \mathrm{~mA} / \mathrm{cm}^{2}$ after 50 cycles (Fig. 2b). A broad irreversible peak, which was observed near $0.7 \mathrm{~V}\left(v s . \mathrm{Li}^{+} / \mathrm{Li}\right)$ during the first lithiation cycle, is most probably due to a formation of a solid electrolyte interface (SEI) layer, as the peak does not appear in the following cycles. [29, 36]. The voltage plateau seen in Fig. 2a is also consistent with formation of a SEI. The irreversible reaction of Li with hydroxyl or fluorine on the surfaces of $\mathrm{Ti}_{3} \mathrm{C}_{2} \mathrm{~T}_{\mathrm{x}}$ layers can also contribute to the first cycle irreversibility [31].

A reversible capacity of $28 \mathrm{mAh} / \mathrm{g}$ was obtained after 50 cycles (Fig. S1b), which is significantly lower than previously reported values (e.g., $110 \mathrm{mAh} / \mathrm{g}$ in Ref. [29]) or the $>400$ $\mathrm{mAh} / \mathrm{g}$ reported in Ref. [25]) for delaminated and loosely packed $\mathrm{Ti}_{3} \mathrm{C}_{2}$. Still, a stable and quite good areal capacity value of $1.7 \mathrm{mAh} / \mathrm{cm}^{2}$ was recorded even after 50 cycles (Fig. 2b). Thus, while the gravimetric specific capacity was low, the dense packing of the MXene flakes resulted in relatively high areal capacity. The reason for the low gravimetric capacities is most probably the high density and large thickness of the electrodes, which limit the access to Li ions and/or electrolyte.

To test this hypothesis, we mixed the $\mathrm{Ti}_{3} \mathrm{C}_{2} \mathrm{~T}_{\mathrm{x}}$ with carbon black, $\mathrm{CB}$, prior to cold pressing. The $\mathrm{CB}$ was added to create open channels between the particles and allow the electrolyte to better penetrate between the layers and enhance Li transport. Different weight percentages $(5,10,15$ wt. \%) of CB (acetylene, 100\% compressed, Alfa Aesar, Ward Hill, MA), 
a common carbon additive used in LIB electrodes, were added to the $\mathrm{Ti}_{3} \mathrm{C}_{2}$ powders. Then each mixture was pressed into a disc - using a load corresponding to a stress of $1 \mathrm{GPa}$ - with a mass loading of $50 \mathrm{mg} / \mathrm{cm}^{2}$. As expected, the CB nanoparticles of few $\mathrm{nm}$ to $100 \mathrm{~nm}$ in diameter reduced the electrode density from $2.14 \mathrm{~g} / \mathrm{cm}^{3}$ at 0 wt. $\%$, to $1.28 \mathrm{~g} / \mathrm{cm}^{3}$ at $15 \mathrm{wt}$ \% CB (Fig. S2). Electrodes were prepared from each disc and galvanostatically cycled at a constant current density of $30 \mathrm{~mA} / \mathrm{g}\left(\mathrm{C} / 3,1.5 \mathrm{~mA} / \mathrm{cm}^{2}\right)$ (Fig. 3).

From the results it is apparent that the addition of CB more than doubles both the specific (Fig. 3a) and areal capacities (Fig. 3b) of the electrodes. For example, the disc with 10 wt. \% CB showed a reversible capacity of $97 \mathrm{mAh} / \mathrm{g}$ after 50 cycles, which is over a 3 -fold increase compared to the bare $\mathrm{Ti}_{3} \mathrm{C}_{2}$ disc. As important, the areal capacity after 50 cycles was 5.9 $\mathrm{mAh} / \mathrm{cm}^{2}$ (Fig. 3b). This value is higher than the commercial graphite anode value of 4 $\mathrm{mAh} / \mathrm{cm}^{2}$ or the values reported for other anodes, such as silicon, graphene, etc. [12, 19, 37-41]. 

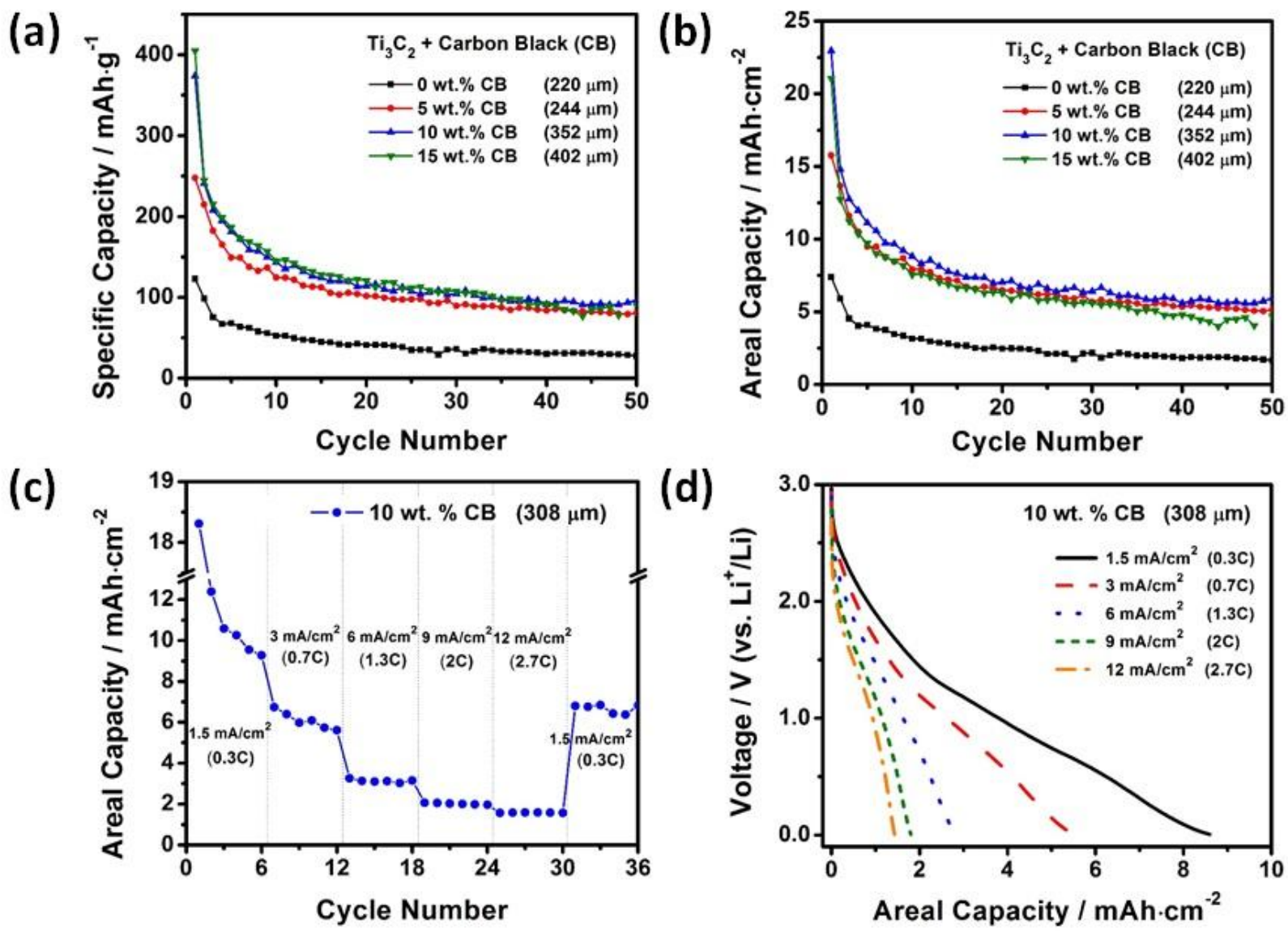

Fig. 3: Electrochemical characteristics of pressed $\mathrm{Ti}_{3} \mathrm{C}_{2} \mathrm{~T}_{\mathrm{x}}$ electrodes as a function of $\mathrm{CB}$ additive content. (a) Specific gravimetric capacity and (b) areal capacity for 0 (black), 5 (red), 10 (blue) and 15 (green) wt. \% CB mixtures. Cells were cycled at a rate of C/3 $\left(30 \mathrm{~mA} / \mathrm{g}, 1.5 \mathrm{~mA} / \mathrm{cm}^{2}\right)$. (c) Areal capacity and (d) charge/discharge curves of a $10 \mathrm{wt}$. \% composite at different current densities. Numbers in parentheses represent electrode thicknesses in (a) and (b) and $\mathrm{C}$ rate in (c) and $(d)$.

From the results shown in Fig. 3b, it is also clear that the exact concentration of $\mathrm{CB}$ in the electrode has little effect on its electrochemical performance. However, since the electrodes with the highest $\mathrm{CB}$ percentage yielded a lower capacity and were also more fragile than the ones containing less $\mathrm{CB}$, we decided to further test the electrodes with no more than $10 \mathrm{wt} \% \mathrm{CB}$. We note in passing that one of the advantages of working with MXenes is their ability to bond together and form relatively strong electrodes without any polymer binder. 
Fig. 3c shows the effect of charging rate of the $10 \mathrm{wt} . \% \mathrm{CB}$ electrodes on their areal capacity. Not surprising, the capacity decreases with increasing charging rates. At the highest charging rate of $12 \mathrm{~mA} / \mathrm{cm}^{2}$ (corresponding to a cycling rate of about $2.7 \mathrm{C}$ ) the areal capacity was $1.58 \mathrm{mAh} / \mathrm{cm}^{2}$ (Fig. 3c). The voltage profiles of this electrode as a function of charging rate are shown in Fig. 3d. Like in the previous work [29], a more or less linear drop in voltage with charging is observed with no voltage plateau. The voltage profiles also become steeper with increasing charging rate.
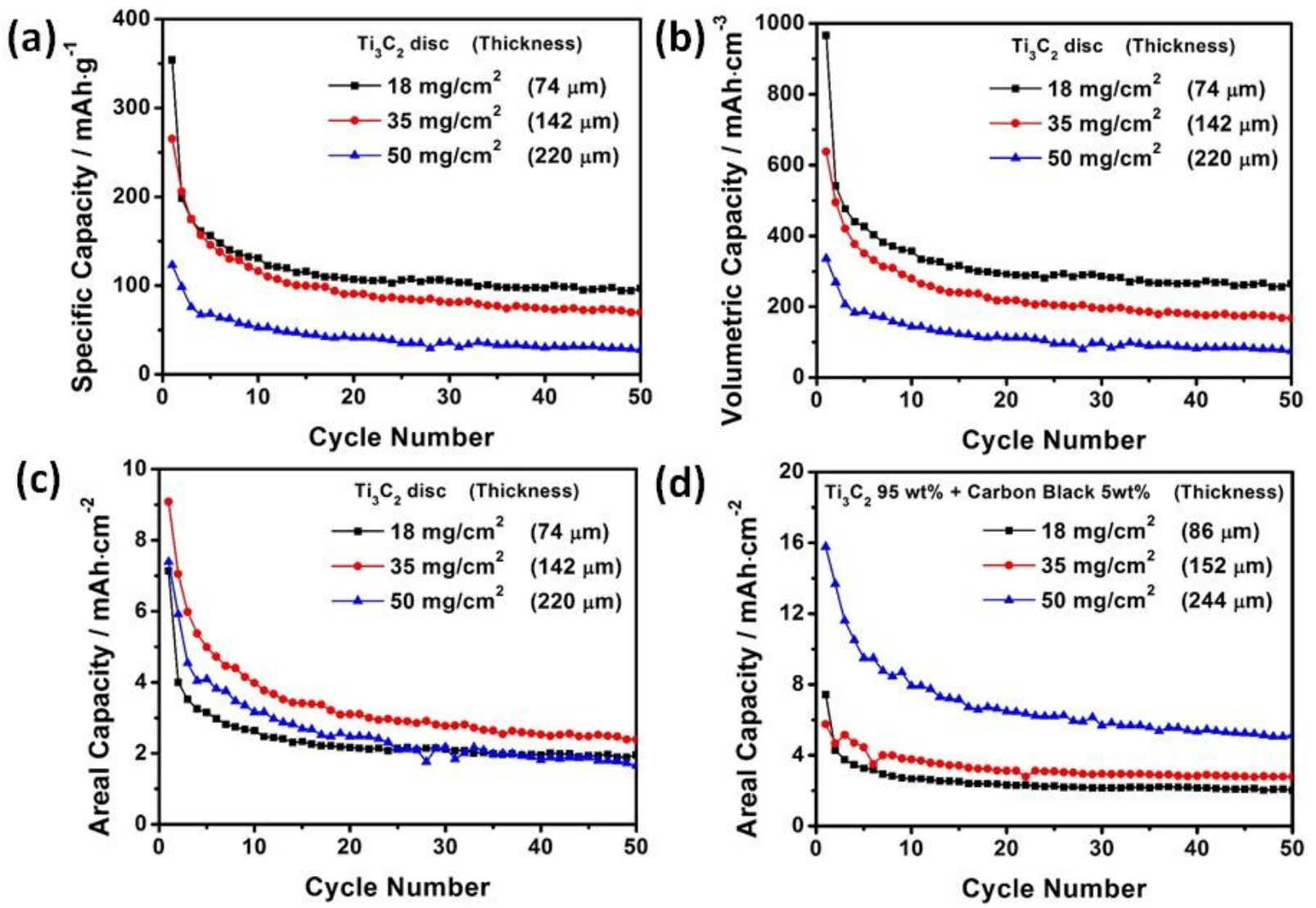

Fig. 4. Effect of electrode thickness on Li-ion capacity; (a) gravimetric, (b) volumetric, and (c) areal capacities of pure $\mathrm{Ti}_{3} \mathrm{C}_{2} \mathrm{~T}_{\mathrm{x}}$ electrodes cycled at $30 \mathrm{~mA} / \mathrm{g}(\mathrm{C} / 3) .74 \mu \mathrm{m}, 142 \mu \mathrm{m}$ and $220 \mu \mathrm{m}$, thick electrodes are shown by black, red and blue symbols, respectively. (d) Areal capacity of 5 wt. \% CB $-\mathrm{Ti}_{3} \mathrm{C}_{2} \mathrm{~T}_{\mathrm{x}}$ electrodes. $86 \mu \mathrm{m}, 152 \mu \mathrm{m}$ and $244 \mu \mathrm{m}$ thick electrodes are shown by black, red and blue symbols, respectively. 
To further explore the effect of electrode geometry on Li capacity, the latter was measured as a function of electrode thicknesses, varying from $74 \pm 2 \mu \mathrm{m}$ to $220 \pm 30 \mu \mathrm{m}$. The results are shown in Figs. 4a-c for pure $\mathrm{Ti}_{3} \mathrm{C}_{2} \mathrm{~T}_{\mathrm{x}}$ electrodes cycled at $30 \mathrm{~mA} / \mathrm{g}(\mathrm{C} / 3)$. Not surprisingly, increasing the electrode thickness resulted in a decrease in both gravimetric (Fig. 4a), and volumetric (Fig. 4b) capacities. The effect of the electrode thickness on areal capacity (Fig. 4c), on the other hand, was not so simple. The $142 \pm 26 \mu \mathrm{m}$ film resulted in the highest areal capacity (Fig. 4c), showing an optimal balance between the various metrics properties. The results also show that the $74 \mu \mathrm{m}$ thick film possessed the highest gravimetric capacity at 97 $\mathrm{mAh} / \mathrm{g}$ (Fig. 4a). At $264 \mathrm{mAh} / \mathrm{cm}^{3}$, the same film also had the highest volumetric capacity (Fig. 4b). The lower specific and volumetric capacities for the thicker discs are most probably due to diffusional limitations. To confirm this hypothesis, 5 wt. $\% \mathrm{CB}-\mathrm{Ti}_{3} \mathrm{C}_{2} \mathrm{~T}_{\mathrm{x}}$ electrodes were tested (Fig. 4d, Fig. S3) and the thickest one showed the highest areal capacity. The 5 wt. \% CB electrodes that were $244 \mu \mathrm{m}$ thick had a comparable capacity to pure $\mathrm{Ti}_{3} \mathrm{C}_{2} \mathrm{~T}_{\mathrm{x}}$ films that were 3 times thinner (Fig. S3). This comparison confirms that the presence of CB particles creates channels for the electrolyte and $\mathrm{Li}$ ions to reach additional active surface sites than in their absence. The value of $5 \mathrm{mAh} / \mathrm{cm}^{2}$ at $\mathrm{C} / 3$ for an electrode that is $244 \mu \mathrm{m}$ thick (Fig. 4d) is noteworthy since it exceeds that of commercial carbon anodes.

To test the applicability of our findings on $\mathrm{Ti}_{3} \mathrm{C}_{2} \mathrm{~T}_{\mathrm{x}}$ to the MXene family of materials in general, we tested another MXene, viz. $\mathrm{Nb}_{2} \mathrm{CT}_{\mathrm{x}}$. [35]. The $\mathrm{Nb}_{2} \mathrm{CT}_{\mathrm{x}}$ powders were mixed with 10 wt. \% $\mathrm{CB}$, before cold pressing a disc under $1 \mathrm{GPa}$ pressure. Similar to $\mathrm{Ti}_{3} \mathrm{C}_{2} \mathrm{~T}_{\mathrm{x}}$, the $\mathrm{Nb}_{2} \mathrm{CT}_{\mathrm{x}}$ electrodes also did not show any voltage plateaus during the charge/discharge process (Fig. S5). Figs. 5a and $\mathbf{5 b}$ compare, the specific and areal capacities of the $\mathrm{Nb}$ - and Ti-based electrodes, respectively; both at a mass loading of $50 \mathrm{mg} / \mathrm{cm}^{2}$. From these results - obtained at a current 
density of $30 \mathrm{~mA} / \mathrm{g}$ (rate of $\mathrm{C} / 3$ ) - it is obvious that $\mathrm{Nb}_{2} \mathrm{CT}_{\mathrm{x}}$ outperforms $\mathrm{Ti}_{3} \mathrm{C}_{2} \mathrm{~T}_{\mathrm{x}}$ on both metrics by about $15 \%$. After 50 cycles, the specific and areal capacities of the $\mathrm{Nb}$-based electrodes were $128 \mathrm{mAh} / \mathrm{g}$ and $6.7 \mathrm{mAh} / \mathrm{cm}^{2}$, respectively. The higher capacities of the $\mathrm{Nb}_{2} \mathrm{CT}_{\mathrm{x}}$ electrodes as compared to their $\mathrm{Ti}_{3} \mathrm{C}_{2} \mathrm{~T}_{\mathrm{x}}$ counterparts, matches previous results on conventional slurry cast electrodes [35]. This is in agreement with theoretical predictions [31]. Since Li intercalates between the MXene layers, thinner $\mathrm{M}_{2} \mathrm{C}$ MXenes are expected to have a higher capacity compared to $\mathrm{M}_{3} \mathrm{C}_{2}$ MXenes. $\mathrm{Nb}_{2} \mathrm{CT}_{\mathrm{x}}$ is a better electrode by more than the $15 \%$ difference shown in Fig. 5a. These comments notwithstanding, it is hereby acknowledged that the voltage profiles of these anodes are still far from ideal. We are currently trying to develop electrodes with low voltage (vs. $\left.\mathrm{Li}^{+} / \mathrm{Li}\right)$ plateaus that would be more suited for LIBs.
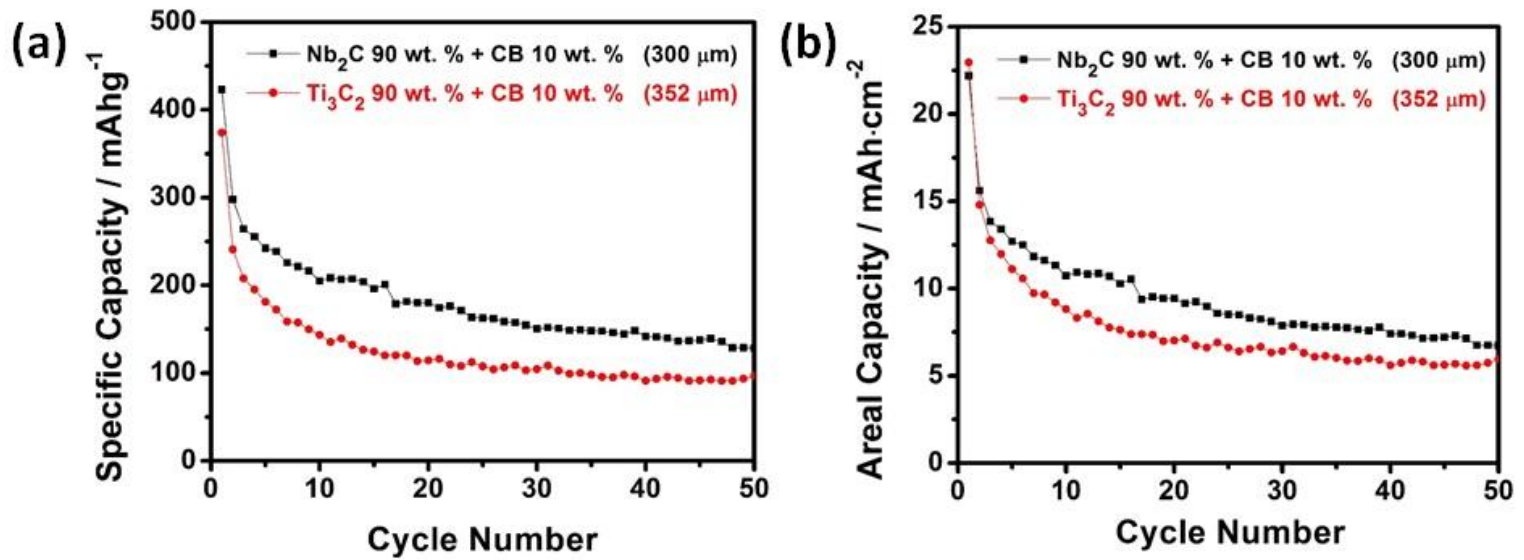

Fig. 5. (a) Gravimetric and (b) areal capacities of $\mathrm{Nb}_{2} \mathrm{CT}_{\mathrm{x}}$ (black symbols) and $\mathrm{Ti}_{3} \mathrm{C}_{2} \mathrm{~T}_{\mathrm{x}}$ (red symbols) pressed discs with $10 \mathrm{wt}$. \% carbon black and cycled at $30 \mathrm{~mA} / \mathrm{g}\left(\mathrm{C} / 3,1.5 \mathrm{~mA} / \mathrm{cm}^{2}\right)$. Numbers in parentheses represent electrode thicknesses.

\section{Conclusions}

Li-ion battery anodes with mass loading up to $50 \mathrm{mg} / \mathrm{cm}^{2}$ were prepared by cold pressing $\mathrm{Ti}_{3} \mathrm{C}_{2} \mathrm{~T}_{\mathrm{x}}$ powders into free-standing, binderless, thick discs. The performance of the latter, 


\section{Electrochimica Acta}

however, was found to deteriorate rapidly with electrode thickness. To solve this problem, electrodes with 10 wt. \% carbon black were fabricated and tested. The areal capacity of 5.9 $\mathrm{mAh} / \mathrm{cm}^{2}$ at $\mathrm{C} / 3$, for an electrode that was $352 \mu \mathrm{m}$ thick, well exceeds that of commercial carbon anodes [12]. Also noteworthy is the fact that the $\mathrm{Ti}_{3} \mathrm{C}_{2}$ anodes with $\mathrm{CB}$ possessed an areal capacity of $1.58 \mathrm{mAh} / \mathrm{cm}^{2}$ even at $2.7 \mathrm{C}$. Even higher areal capacities $-6.7 \mathrm{mAh} / \mathrm{cm}^{2}$ after 50 cycles at a rate of $\mathrm{C} / 3$ - were obtained for $\mathrm{Nb}_{2} \mathrm{CT}_{\mathrm{x}}-10$ wt. \% $\mathrm{CB}$ electrodes. Thus, even though cold-pressed MXene electrodes have a somewhat lower gravimetric capacity than the best commercial graphite, very high mass loadings can be achieved for the former, which leads to high areal capacities $\left(5.9 \mathrm{mAh} / \mathrm{cm}^{2}\right)$. These results suggest that MXenes can be assembled into LIB anodes with high mass loadings and high areal capacities that could be useful in practical applications.

\section{ACKNOWLEDGMENT}

The authors are thankful to Dr. Babak Anasori and Zheng Ling for helpful discussions, MAX phase synthesis and help with SEM analysis, and Dr. Chunfeng Hu, Michael Ghidiu for XRD analysis. S. J. K. acknowledges support from the BK-21 Plus program. This work was supported by the Assistant Secretary for Energy Efficiency and Renewable Energy, Office of Vehicle Technologies of the U.S. Department of Energy under Contract No. DE-AC02-05CH11231, subcontract No. 6951370, under the Batteries for Advanced Transportation Technologies (BATT) Program. 
Electrochimica Acta

REFERENCES

(1) J.M. Tarascon, M. Armand, Issues and challenges facing rechargeable lithium batteries. Nature 414 (2001) 359-367.

(2) B. Dunn, H. Kamath, J.M. Tarascon, Electrical Energy Storage for the Grid: A Battery of Choices. Science 334 (2011) 928-935.

(3) F.T. Wagner, B. Lakshmanan, M.F. Mathias, Electrochemistry and the Future of the Automobile. J. Phys. Chem. Lett. 1 (2010) 2204-2219.

(4) B. Kang, G. Ceder, Battery materials for ultrafast charging and discharging. Nature 458 (2009) 190-193.

(5) J.R. Dahn, T. Zheng, Y. Liu, J.S. Xue, Mechanisms for Lithium Insertion in Carbonaceous Materials. Science 270 (1995) 590-593.

(6) Q. Tang, Z. Zhou, Graphene-analogous low-dimensional materials. Prog. Mater. Sci. 58 (2013) 1244-1315.

(7) Y. Jing, Z. Zhou, C.R. Cabrera, Z. Chen, Graphene, inorganic graphene analogs and their composites for lithium ion batteries. J. Mater. Chem. A 2 (2014) 12104-12122.

(8) J. Cabana, L. Monconduit, D. Larcher, M.R. Palacín, Beyond Intercalation-Based Li-Ion Batteries: The State of the Art and Challenges of Electrode Materials Reacting Through Conversion Reactions. Adv. Mater. 22 (2010) E170-E192. 
(9) S. Yang, X. Feng, S. Ivanovici, K. Müllen, Fabrication of Graphene-Encapsulated Oxide Nanoparticles: Towards High-Performance Anode Materials for Lithium Storage. Angew. Chem. Int. Ed. 49 (2010) 8408-8411.

(10) G.N. Zhu, Y.G. Wang, Y.Y. Xia, Ti-based compounds as anodes for Li-ion batteries. Energy Environ. Sci. 6 (2012) 6652-6667.

(11) C.K. Chan, H. Peng, G. Liu, K. McIlwrath, X.F. Zhang, R.A. Huggins, Y. Cui, Highperformance lithium battery anodes using silicon nanowires. Nat. Nanotechnol. 3 (2008) 3135.

(12) N. Liu, Z. Lu, J. Zhao, M.T. McDowell, H.W. Lee, W. Zhao, Y. Cui, A pomegranateinspired nanoscale design for large-volume-change lithium battery anodes. Nat. Nanotechnol. 9 (2014) 187-192.

(13) J. Liu, K. Song, C. Zhu, C.C. Chen, P.A. van Aken, J. Maier, Y. Yu, Ge/C Nanowires as High-Capacity and Long-Life Anode Materials for Li-Ion Batteries. ACS Nano 8 (2014) 7051-7059.

(14) Y. Xu, Q. Liu, Y. Zhu, Y. Liu, A. Langrock, M.R. Zachariah, C. Wang, Uniform NanoSn/C Composite Anodes for Lithium Ion Batteries. Nano Lett. 13 (2013) 470-474.

(15) M.N. Obrovac, V.L. Chevrier, Alloy Negative Electrodes for Li-Ion Batteries. Chem. Rev. 114 (2014) 11444-11502.

(16) Y. Gogotsi, P. Simon, True Performance Metrics in Electrochemical Energy Storage. Science 334 (2011) 917-918. 
Electrochimica Acta

(17) J.B. Goodenough, Y. Kim, Challenges for rechargeable batteries, J. Power Sources 19 (2011) 6688-6694.

(18) J.S. Kim, T.H. Hwang, B.G. Kim, J. Min, J.W. Choi, A Lithium-Sulfur Battery with a High Areal Energy Density. Adv. Funct. Mater. 24 (2014) 5359-5367.

(19) R. Yi, J. Zai, F. Dai, M.L. Gordin, D. Wang, Dual conductive network-enabled graphene/Si-C composite anode with high areal capacity for lithium-ion batteries. Nano Energy 6 (2014) 211-218.

(20) B. Wang, X. Li, T. Qiu, B. Luo, J. Ning, J. Li, X. Zhang, M. Liang, L. Zhi, High Volumetric Capacity Silicon-Based Lithium Battery Anodes by Nanoscale System Engineering. Nano Lett. 13 (2013) 5578-5584.

(21) M. Naguib, M. Kurtoglu, V. Presser, J. Lu, J. Niu, M. Heon, L. Hultman, Y. Gogotsi, M.W. Barsoum, Two-Dimensional Nanocrystals Produced by Exfoliation of $\mathrm{Ti}_{3} \mathrm{AlC}_{2}$. Adv. Mater. 23 (2011) 4248-4253.

(22) M. Naguib, O. Mashtalir, J. Carle, V. Presser, J. Lu, L. Hultman, Y. Gogotsi, M.W. Barsoum, Two-Dimensional Transition Metal Carbides. ACS Nano 6 (2012) 1322-1331.

(23) M. Naguib, V.N. Mochalin, M.W. Barsoum, Y. Gogotsi, $25^{\text {th }}$ Anniversary Article: MXenes: A New Family of Two-Dimensional Materials. Adv. Mater. 26 (2014) 992-1005.

(24) M.W. Barsoum, MAX Phases: Properties of Machinable Ternary Carbides and Nitrides (Wiley, Weinheim, Germany). 2013. 
(25) O. Mashtalir, M. Naguib, V.N. Mochalin, Y. Dall'Agnese, M. Heon, M.W. Barsoum, Y. Gogotsi, Intercalation and delamination of layered carbides and carbonitrides. Nat. Commun. $4(2013) 1716$.

(26) Z. Ling, C.E. Ren, M.Q. Zhao, J. Yang, J.M. Giammarco, J. Qiu, M.W. Barsoum, Y. Gogotsi, Flexible and conductive MXene films and nanocomposites with high capacitance. Proc. Natl. Acad. Sci. 111 (2014) 16676-16681.

(27) M. Ghidiu, M.R. Lukatskaya, M.Q. Zhao, Y. Gogotsi, M.W. Barsoum, Conductive twodimensional titanium carbide 'clay' with high volumetric capacitance. Nature 516 (2014) $78-81$.

(28) M.Q. Zhao, C.E. Ren, Z. Ling, M.R. Lukatskaya, C. Zhang, K.L. Van Aken, M.W. Barsoum, Y. Gogotsi, Flexible MXene/Carbon Nanotube Composite Paper with High Volumetric Capacitance. Adv. Mater. (2014) DOI: 10.1002/adma.201404140.

(29) M. Naguib, J. Come, B. Dyatkin, V. Presser, P.L. Taberna, P. Simon, M.W. Barsoum, Y. Gogotsi, MXene: a promising transition metal carbide anode for lithium-ion batteries. Electrochem. Commun. 16 (2012) 61-64.

(30) D. Sun, M. Wang, Z. Li, G. Fan, L. Fan, A. Zhou, Two-dimensional Ti3C2 as anode material for Li-ion batteries. Electrochem. Commun. 47 (2014) 80-83.

(31) Y. Xie, M. Naguib, V.N. Mochalin, M.W. Barsoum, Y. Gogotsi, X. Yu, K.W. Nam, X.Q. Yang, A.I. Kolesnikov, P.R.C. Kent, Role of Surface Structure on Li-Ion Energy Storage Capacity of Two-Dimensional Transition-Metal Carbides. J. Am. Chem. Soc. 136 (2014) $6385-6394$. 
(32) C. Eames, M.S. Islam, Ion Intercalation into Two-Dimensional Transition-Metal Carbides: Global Screening for New High-Capacity Battery Materials. J. Am. Chem. Soc. 136 (2014) $16270-16276$.

(33) D. Er, J. Li, M. Naguib, Y. Gogotsi, V.B. Shenoy, $\mathrm{Ti}_{3} \mathrm{C}_{2}$ MXene as a High Capacity Electrode Material for Metal (Li, Na, K, Ca) Ion Batteries. ACS Appl. Mater. Interfaces 6 (2014) 11173-11179.

(34) Q. Tang, Z. Zhou, P. Shen, Are MXenes Promising Anode Materials for Li Ion Batteries? Computational Studies on Electronic Properties and Li Storage Capability of $\mathrm{Ti}_{3} \mathrm{C}_{2}$ and $\mathrm{Ti}_{3} \mathrm{C}_{2} \mathrm{X}_{2}(\mathrm{X}=\mathrm{F}, \mathrm{OH})$ Monolayer. J. Am. Chem. Soc. 134 (2012) 16909-16916.

(35) M. Naguib, J. Halim, J. Lu, K.M. Cook, L. Hultman, Y. Gogotsi, M.W. Barsoum, New Two-Dimensional Niobium and Vanadium Carbides as Promising Materials for Li-Ion Batteries. J. Am. Chem. Soc. 135 (2013) 15966-15969.

(36) M.B. Pinson, M.Z. Bazant, Theory of SEI Formation in Rechargeable Batteries: Capacity Fade, Accelerated Aging and Lifetime Prediction. J. Electrochem. Soc. 160 (2013) A243A250.

(37) V.L. Chevrier, L. Liu, D.B. Le, J. Lund, B. Molla, K. Reimer, L.J. Krause, L.D. Jensen, E. Figgemeier, K.W. Eberman, Evaluating Si-Based Materials for Li-Ion Batteries in Commercially Relevant Negative Electrodes. J. Electrochem. Soc. 161 (2014) A783-A791.

(38) X. Li, M. Gu, S. Hu, R. Kennard, P. Yan, X. Chen, C. Wang, M.J. Sailor, J.G. Zhang, J. Liu, Mesoporous silicon sponge as an anti-pulverization structure for high-performance lithiumion battery anodes. Nat. Commun. 5 (2014) 4105. 
(39) Q. Xiao, Y. Fan, X. Wang, R.A. Susantyoko, Q. Zhang, A multilayer Si/CNT coaxial nanofiber LIB anode with a high areal capacity. Energy Environ. Sci. 7 (2014) 655-661.

(40) X. Wang, Y. Fan, R.A. Susantyoko, Q. Xiao, L. Sun, D. He, Q. Zhang, High areal capacity $\mathrm{Li}$ ion battery anode based on thick mesoporous $\mathrm{Co}_{3} \mathrm{O}_{4}$ nanosheet networks. Nano Energy 5 (2014) 91-96.

(41) Q. Cheng, Z. Song, T. Ma, B.B. Smith, R. Tang, H. Yu, H. Jiang, C.K. Chan, Folding Paper-Based Lithium-Ion Batteries for Higher Areal Energy Densities. Nano Lett. 13 (2013) 4969-4974. 